\title{
STRUCTURE OF EPICUTICULAR WAXES ON SPIKES AND LEAF SHEATHS OF BARLEY AS REVEALED BY A DIRECT PLATINUM REPLICA TECHNIQUE
}

\author{
by \\ DAVID SIMPSON ${ }^{1,3}$ and PENNY von WETTSTEIN-KNOWLES ${ }^{1,2}$ \\ 'Department of Physiology, Carlsberg Laboratory, \\ Gamle Carlsberg Vej 10, DK-2500 Copenhagen Valby \\ 2Institute of Genetics, University of Copenhagen, \\ Øster Farimagsgade 2A, DK-1353 Copenhagen K \\ ${ }^{3}$ Present address: CSIRO, Division of Horticulture Research, \\ P.O. Box 350, Adelaide, South Australia 5001
}

Keywords: $\beta$-diketones, primary alcohols, wax tubes, wax plates, negative staining, glumes, lemmas, awns, eceriferum mutants

A direct platinum replica technique is described for studying cuticle surfaces with few or no projecting wax structures. It is furthermore demonstrated that the structure of some small plate waxes can be elucidated using negative staining.

Three types of epicuticular waxes are present on barley cuticular surfaces: (i) long, thin tubes and $\beta$-diketone lipids characterize that on the glumes, lemmas and uppermost leaf sheaths; (ii) highly lobed plates, large amounts of primary alcohols (predominantly $\mathrm{C}_{26}$ ) and an absence of $\beta$-diketone lipids characterize that on the leaf blades and lower leaf sheaths; and (iii) thin plates, frequently horizontal to the surface, major amounts of hydrocarbons and esters and an absence of $\beta$-diketone lipids characterize that on the awns. When mutations cause the absence or a major reduction of the dominating lipids in one of the first two types of waxes, the wax deposits resemble the third type.

The mutation $c e r-\mathrm{s}^{31}$ restricts the presence of wax tubes to patches on the lemmas, paleas and glumes giving them a grainy appearance. While the effect is greatest on the lemmas of the median floret rows, the reduction of

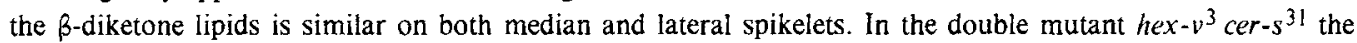
lateral florets become fertile, but the differential effect of $c e r-s^{31}$ on the median and lateral rows is retained.

Abbreviations: $\mathrm{C} / \mathrm{Au} / \mathrm{Pd}$ replica $=$ gold-palladium pre-shadowed carbon replica; $\mathrm{GLC}=$ gas liquid chromatography; $\mathrm{Pt} / \mathrm{C}$ replica $=$ direct platinum shadowed replica; $\mathrm{TLC}=$ thin layer chromatography. 


\section{INTRODUCTION}

The presence of epicuticular waxes on the surfaces of the barley plant is controlled by the eceriferum (cer) genes. When mutants in these genes are selected in the field, they are classified according to the appearance of the leaf blades, spikes and/or leaf sheaths plus internodes. In essence the latter two categories describe the phenotypes of the lemma and upper portion of the culm, respectively. Striking differences in wax composition and structure occur when the boundaries between these three parts of the plant are crossed. Changes in composition which result in altered wax body structure give rise to the mutant phenotypes (see 34). A few mutants have been found which do not alter the phenotype uniformly over the entire surface area of one or more of the three plant parts. To illustrate, the zebra-like alternating blue grey and green bands of the leaf sheaths and internodes of $c e r-z w^{286}$ (19) are due to the presence and absence of the $\beta$-diketone lipids, respectively (von Wettstein-Knowles, unpublished). Such observations suggest that wax synthesis and deposition in barley is cell specifically determined (35).

Recently the mutation cer-s ${ }^{31}$ was noted to alter the phenotype of the fertile caryopses of the median rows but not that of the sterile caryopses of the lateral rows. To understand the pattern formation induced by this mutation, the chemistry and structure of the wax on these individual parts of the spike were studied. Awn wax is already known to be different chemically from that on the rest of the spike (35). Herein we report the results of such combined analysis. The structural studies were made possible by the development of an improved replica technique. Simultaneously we have investigated the structure and chemistry of the waxes on the lower leaf sheaths of various genotypes so as to provide a more complete picture of wild type barley epicuticular waxes.

\section{MATERIALS AND METHODS}

\subsection{Plants}

Seeds of barley (Hordeum vulgare L.) cv. Bonus as well as of the eceriferum mutants cer$c^{36}$ and $-\mathrm{s}^{31}(18)$, of the six row hexastichon mutant hex $-v^{3}(8)$ and of the double mutant hex$v^{3}$ cer-s $\mathrm{s}^{31}$ were planted in a standard soil
(Enhetsjord K, W. Platin \& Co.; Sweden) and grown in a model WE-95 Percival growth chamber with 23.5 hours of light $(8,500$ lux $)$ and 0.5 hours of dark. Pellets of NPK $(21: 4: 10)+M g$ (Superfos A/S; Denmark) were placed on the soil when the third leaves were emerging. Since the watering was from rockwool mats (Grodania; Denmark) placed below the pots, the pellets dissolved slowly providing nutrients throughout growth of the plants. The thermoperiodicity was 16 hours at $15^{\circ} \mathrm{C}$ and 8 hours, which included the 0.5 hours dark period, at $10^{\circ} \mathrm{C}$ with a relative humidity of $80 \%$. The Chinese Spring wheat plants (22) and the leaf blade barley mutant cer-p $p^{888}(7,19,29)$ were grown in a Percival PWG-108 growth chamber as detailed previously (22). The Bonus barley used for measurements of the internode lengths was grown in the Stockholm Phytotron under similar conditions (29).

The double mutant hex-v $v^{3} e r-s^{31}$ was constructed by crossing the two single mutants in the field at Svalöf, Sweden in the summer of 1976. The two markers had been reported to be $24 \pm 4$ map units apart on chromosome 2 (27). The $F_{1}$ was grown in the Stockholm Phytotron in the winter of 1976-1977 and the $F_{2}$ was planted in the field at Risø, Denmark in the summer of 1977 . Seeds were collected from the double mutant plants.

Lengths of the five uppermost internodes (excluding nodes) of Bonus plants were measured with a millimetre scale. Each measurement reported is the average from the first three tillers of five plants at heading time (29).

Pictures of median and lateral row seeds, held in position with modelling clay, were taken with the aid of an American Optical, Stereo Star Zoom Microscope fitted with a Carlsberg Macrofluorescence Unit (Gibbons \& Munck, U.S. Patent Application No. 088.320, 1979). The filter combination SWP-485 nm primary and KV-418 nm secondary (Optical Laboratory, Lundtofte, Denmark) was chosen to obtain maximum contrast between the wax and the chlorophyll present within the outer cells of the seeds. While chlorophyll absorbed the major part of the primary light, the wax reflected these wavelengths. The photographs were taken with an AO EXPO Star unit using Agfapan professional AP 25 film. 


\subsection{Chemical analyses}

Wax was collected from total spikes, awns, median row seeds or lateral row seeds by dipping in two consecutive containers of re-distilled chloroform $(15+10 \mathrm{sec}$.) (see 29). Glumes were collected in a fluted paper filter and rinsed with several small aliquots of re-distilled chloroform. Contact of cut surfaces with chloroform results in some contamination of the wax samples by internal lipids (see 29). These remain at the origin in the thin layer chromatographic (TLC) system used. Wax from given segments of leaf sheaths was collected using swab sticks prewashed with chloroform (22).

The component lipid classes of the isolated waxes were resolved with the aid of TLC using silica gel $\mathrm{H}$ (Merck) coated plates and benzene as the developing solvent. They were visualized by spraying with $55 \% \mathrm{H}_{2} \mathrm{SO}_{4}$ containing $0.6 \%$ (w/v) $\mathrm{K}_{2} \mathrm{Cr}_{2} \mathrm{O}_{7}$, followed by charring. Preparative TLC plates (silica gel $\mathrm{H}$, benzene) were run to isolate the primary alcohols. Acetate derivatives were prepared $(29,36)$ and gas liquid chromatography (GLC) carried out as previously specified on $3 \%$ SP-2100 columns (36).

\subsection{Structural analyses}

Gold-palladium pre-shadowed carbon replicas $(\mathrm{C} / \mathrm{Au} / \mathrm{Pd})$ using a single plastic backing technique and negative stain preparations were made as described in references 22 and 31 , respectively, from the appropriate surfaces of the heading plants. The grids were examined in a Siemens Elmiskop 1A, operated at $80 \mathrm{kV}$.

Platinum shadowed replicas $(\mathrm{Pt} / \mathrm{C})$ were prepared from different cuticle surfaces of heading plants. The tissue to be examined was dissected from the plant, care being taken to avoid touching the surface. Large tissue was trimmed to a size of approximately $2 \times 4 \mathrm{~mm}$ with a scalpel, and transferred with forceps to the three-specimen cold stage of a Balzers BAF 300 freeze-etch apparatus. Smaller tissue structures such as glumes or awns could not be trimmed on all sides. Between three and six specimens, depending on size, were clamped in the cold-stage. The evaporation chamber was evacuated and when the vacuum had reached $1 \times 10^{-3}$ torr, the stage was cooled to $-100^{\circ} \mathrm{C}$. When this temperature was reached, the vacuum was $1 \times 10^{-5}$ torr, or better. The specimens were immediately shadowed with platinum-carbon at an angle of $45^{\circ}$ from an electron evaporation gun, to an average thickness of $20 \AA$, as determined by a quartz crystal thin film monitor. This was followed by a 200-300 $\AA$ thick layer of carbon deposited at an angle of $90^{\circ}$ from a second electron beam evaporation gun, providing mechanical stability to withstand subsequent cleaning operations.

The frozen replicated specimens were thawed and floated onto a $15 \%$ aqueous solution of sodium hypochlorite for 2 hours. They were subsequently transferred with a platinum loop into distilled water and left overnight in $40 \%$ $(\mathrm{w} / \mathrm{v})$ chromic acid to remove as much as possible of the organic material from the replica. Usually the cuticle resisted attack, and remained attached to the replica, particularly with structures such as the awns and glumes, which had irregular, untrimmed edges. Replicas could be separated from the cuticle by taking the specimens from the chromic acid into distilled water (two washes) and then into acetone, using a platinum loop. The specimen was then transferred into distilled water, where the forces generated by the difference in the surface tension between water and acetone usually resulted in separation of the replica from the remaining organic material. If this was not successful the first time, the specimen was returned to the acetone and then transferred back into water. Other techniques, such as direct transfer from sodium hypochlorite into chromic acid (with subsequent generation of chlorine gas) or washing with chloroform-methanol might be useful for particularly difficult replicas, but were not found to be necessary in this study. After three washes in distilled water, replicas were picked up on hydrophilic 400 mesh copper grids and examined in a Siemens Elmiskop 102, operated at $80 \mathrm{kV}$.

All micrographs are printed as positives, directly from the original negatives (so that the shadows appear white), and the direction of shadowing is from bottom to top, according to conventions used for freeze-fracturing. 
D. Simpson and P. von Wettstein-Knowles: Structure of barley waxes

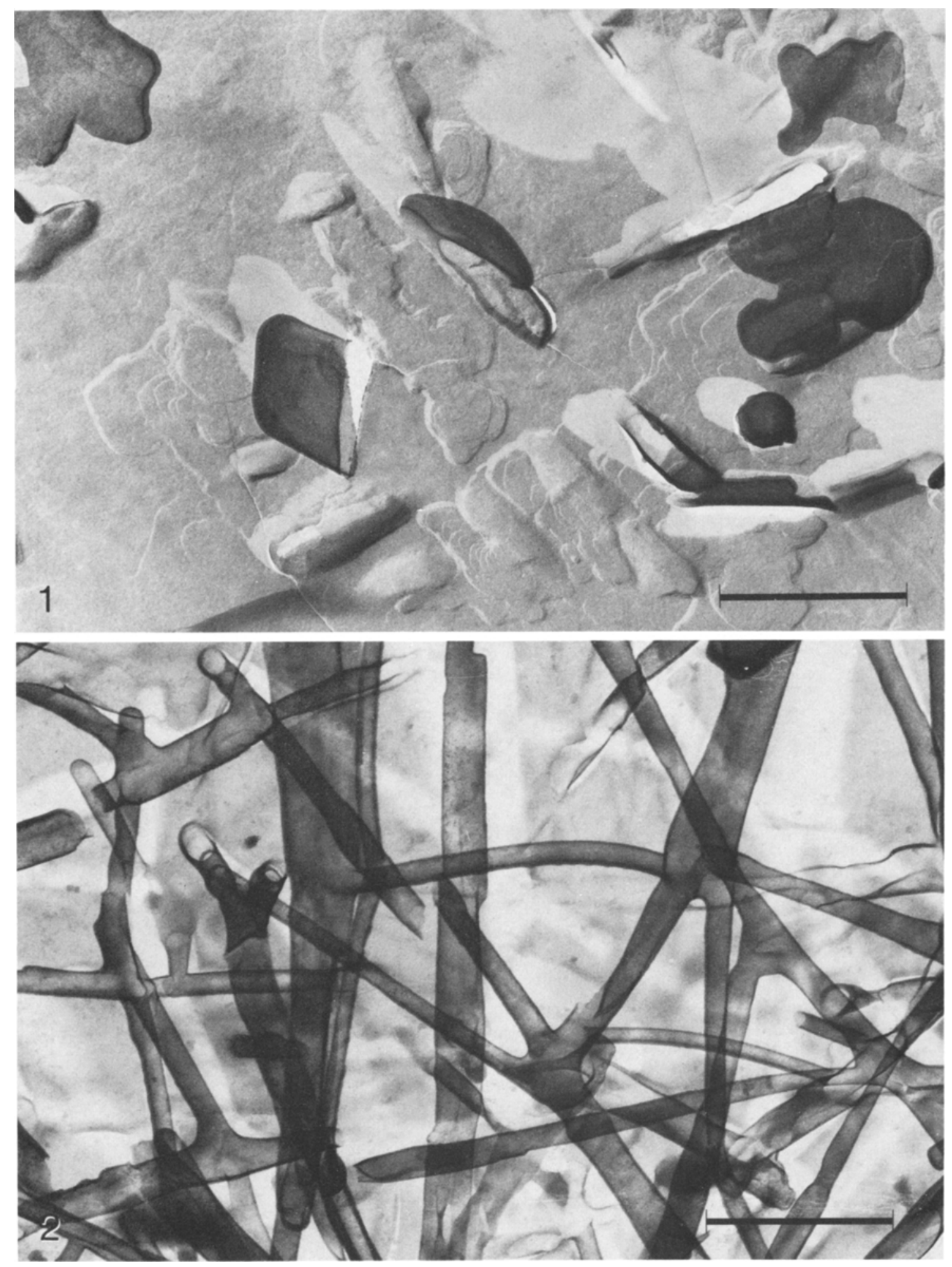


Figure 1. Vertical and horizontal wax plates characterizing the surface of a Bonus barley awn as revealed by a $\mathrm{Pt} / \mathrm{C}$ replica from frozen tissue.

Bar $=1 \mu \mathrm{m}$.

Figure 2. Portions of long, thin wax tubes characterizing the adaxial surface of a Bonus barley glume as revealed by a $\mathrm{Pt} / \mathrm{C}$ replica from frozen tissue.

Bar $=1 \mu \mathrm{m}$.

\section{RESULTS AND DISCUSSION}

\subsection{Spike waxes}

The structures of epicuticular waxes on the awns and glumes of Bonus barley as revealed by the direct platinum replica technique are illustrated in Figures 1 and 2, respectively. The thin plates on the awns are most frequently horizontal to the cuticle surface, but may also rise vertically from the surface. Plates with the same structures and distributions were also found on the awns of $c e r-c^{36}$. In its overall appearance the awn surface is most similar to that of $c e r-j^{59}$ leaves (20), although the latter has more moundlike wax structures than vertical thin ones. While both surfaces of the glumes can be seen in a dissecting microscope to be grey with wax, replicas could only be prepared from the adaxial surface, which lacks the numerous, long hairs of the abaxial surface. Long, thin tubes densely covered the adaxial glume surface and flat plates lying on the surface are occasionally seen beneath the tubes. The comparison of wax structures on the glumes and awns suggests that $\beta$ - and/or hydroxy- $\beta$-diketones are important components of the wax on the glumes but absent on awns (30). This was verified by a TLC separation of the wax classes from these two parts of the spike which also showed that hydrocarbons are a major constituent of glume wax (Figure 3). Awn waxes, on the other hand, contribute a large proportion of the esters to a total Bonus spike wax preparation.

The dorsal cuticle surface of the median (i.e., developed) floret lemma was earlier shown to be covered with long, thin tubes (29). Several cer spike mutants, selected for the loss or reduction of the characteristic blue grey color, have been shown to have an altered number and/or structure of the long, thin wax tubes on the median floret lemmas (30). In such mutants the phenotype of the lemmas on the sterile lateral florets was visually similar to that of the median floret lemmas. Frequently, however, the glumes still exhibited some blue grey color. This was especially true for those cer spikes classified as having a reduced amount of wax. These observations have been extended to more than forty additional mutants over the past years. The single striking exception to this general pattern occurs on cer-s $\mathrm{s}^{31}$ spikes, where both lateral florets and all the glumes are distinctly blue grey in color, only the median floret lemmas being yellow green.

To determine whether the expression of cer-

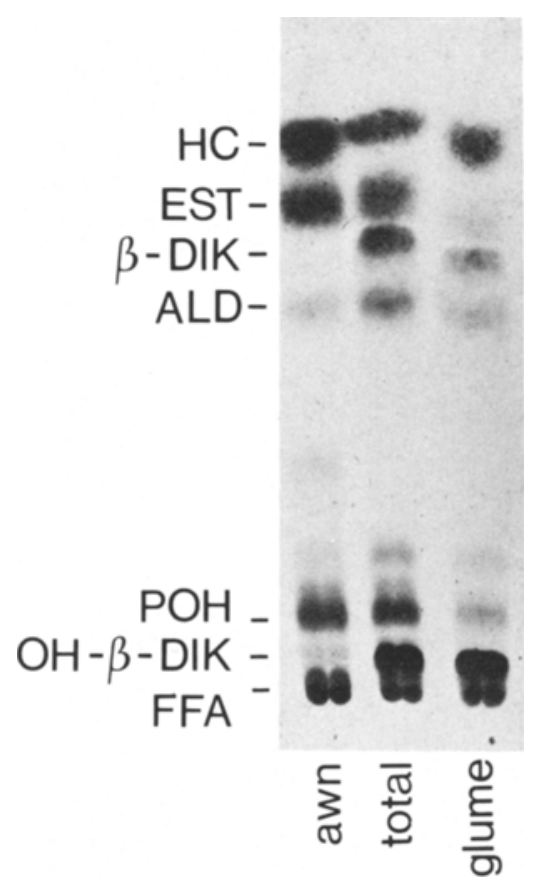

Figure 3. Composition of the epicuticular waxes present on total spikes, awns and glumes of Bonus barley as revealed by TLC.

See section 2.2 . 

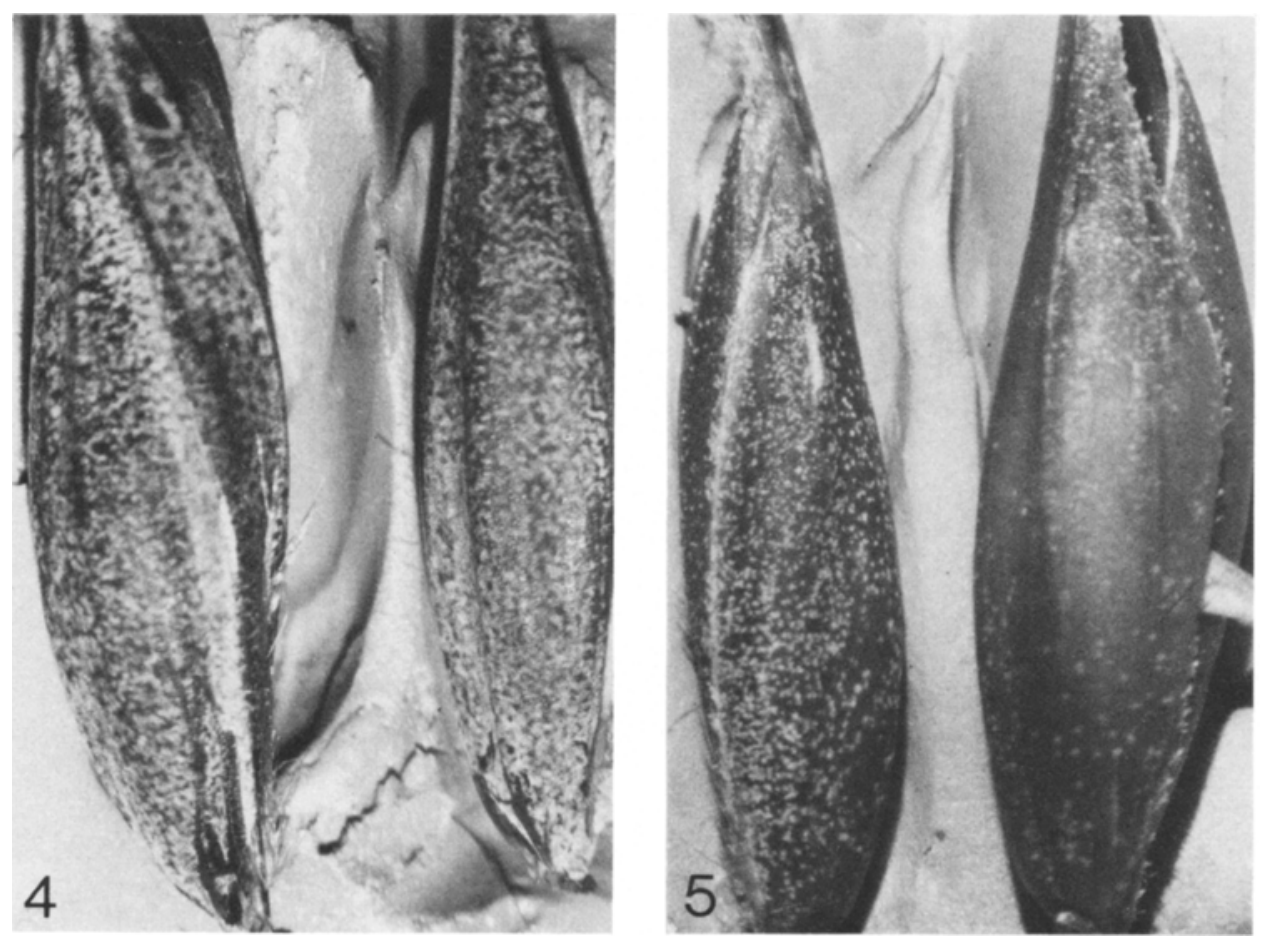

Figure 4. Distribution of the epicuticular wax on median (right) and lateral (left) lemmas of $h e x-v^{3}$ as seen in a dissecting microscope.

Note scratches in the wax at base of both lemmas. $\times 9.5$.

Figure 5. Distribution of the epicuticular wax on lateral (right) and median (left) lemmas of hex-v $v^{3} c^{2}-s^{31}$ as seen in a dissecting microscope.

$\times 9.2$.

$s^{31}$ requires the lemmas to be on fertile florets, cer- $\mathrm{s}^{31}$ plants were crossed to hex $-v^{3}$ plants in which the four lateral rows of florets are fertile. Figure 4 shows that while the wax cover on hex$v^{3}$ median and lateral lemmas is dense it is not uniformly distributed over the entire surface. This uneven distribution was also detected earlier in carbon replica preparations of lemmas (29). Dipping in chloroform removes the cover verifying its lipid nature. Plants homozygous for both markers were easily identified in the $F_{2}$ generation, since a clear difference between the color of the median and lateral floret lemmas occurred on some of the hex $-v^{3}$ spikes. That this difference reflects a differential distribution of wax on the two types of lemmas is illustrated in Figure 5 . As can be seen by comparing lemmas of hex $-v^{3}$ cer-s $s^{31}$ plants (Figure 5) with those of $h e x-\nu^{3}$ plants (Figure 4), cer $-s^{31}$ reduces the total wax coating, visible in the dissecting microscope,

Figure 6. Horizontal wax plates and portions of long, thin tubes characteristic for wax grains on hex-v $v^{3}$ cer-s ${ }^{31}$ lateral lemmas as revealed by a $\mathrm{Pt} / \mathrm{C}$ replica from frozen tissue.

Bar $=1 \mu \mathrm{m}$.

Figure 7. Horizontal wax plates characterizing the cuticle surface between the sparse wax grains on hex- $\nu^{3} c e r-$ $s^{31}$ median lemmas as revealed by a $\mathrm{Pt} / \mathrm{C}$ replica from frozen tissue.

Bar $=1 \mu \mathrm{m}$. 
D. Simpson and P. von Wettstein-Knowles: Structure of barley waxes

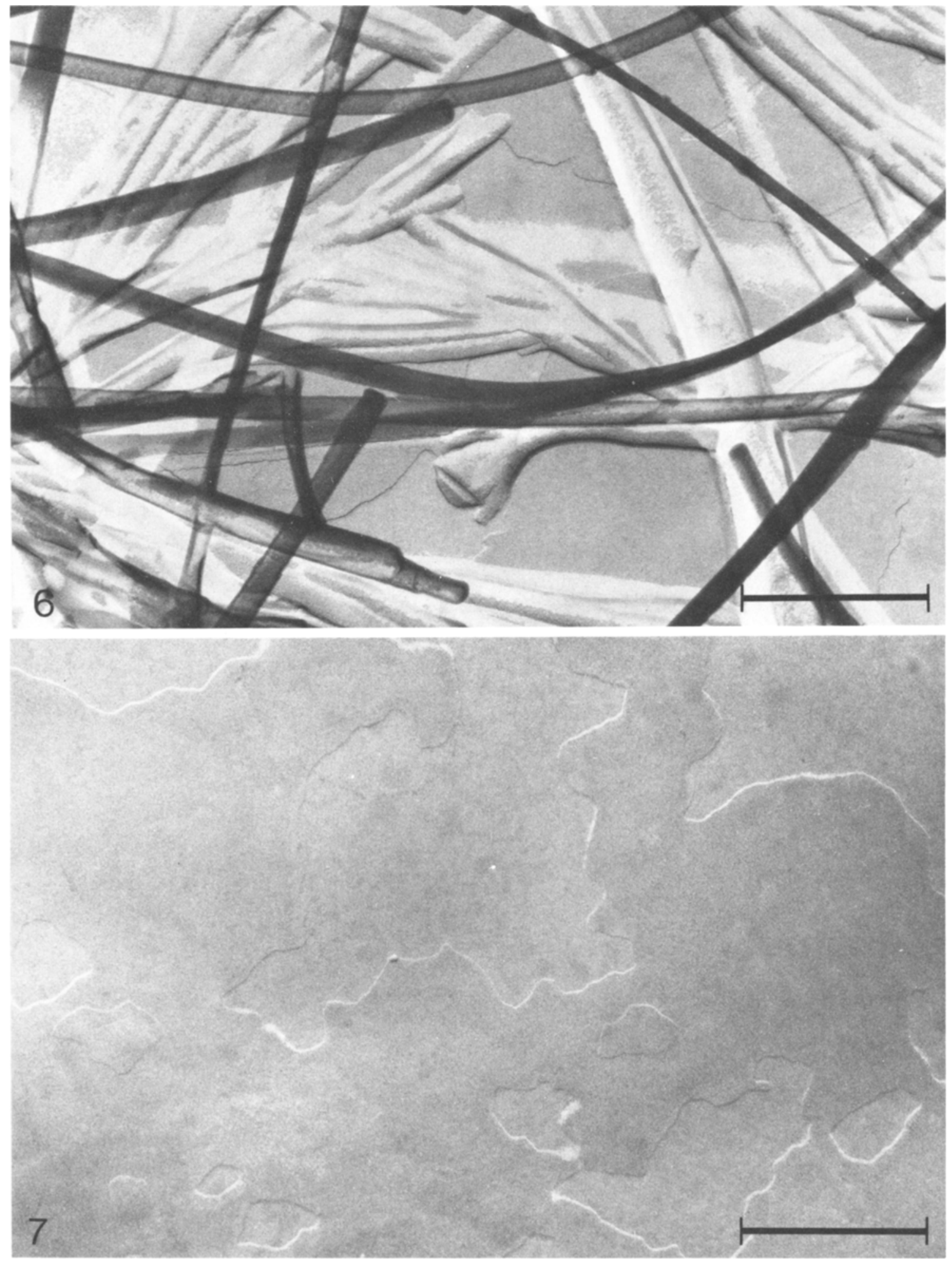


on both types of lemmas, but far more drastically on those of the median than the lateral florets. The wax accumulations on the surface of these lemmas give them on inspection with the unaided eye a grainy appearance. The extent of the wax reduction on the median lemmas is very irregular with most of the wax grains occurring toward the basal or apical ends. The effect of cer$s^{31}$ on the distribution of visible wax on the median and lateral paleas is analogous. Thus lemma wax coatings occur in three different densities: those on (i) hex $-v^{3}$ median and lateral, (ii) hex $-v^{3} c e r-s^{31}$ lateral and (iii) hex- $v^{3} c e r-s^{31}$ median florets. The marked difference in the total number of wax grains on the two types of $h e x-v^{3} c e r-s^{31}$ lemmas is far greater than any observed difference in the sizes of these lemmas. Thus, the differential expression of cer- $\mathrm{s}^{31}$ on median and lateral floret lemmas in a two row barley is not directly correlated with seed development.

Inspection of both surfaces of all glumes from $h e x-v^{3} c e r-s^{31}$ spikes revealed that cer-s ${ }^{31}$ also reduces the wax coat on these cuticle surfaces. As in the case of the lateral floret lemmas, however, the reduction is not sufficient to be detectable by the unaided eye.

To determine whether cer-s ${ }^{31}$ influences wax ultrastructure in addition to its distribution, replicas were prepared by the direct platinum replica method. Figure 6 shows that the grains of wax on hex $-v^{3}$ cer-s ${ }^{31}$ lemmas consist of long, thin tubes. They are quite similar to the tubes of the dense wax coats of hex $-v^{3}$ lemmas. The only detected wax structures between the clusters of tubes composing the visible grains are horizontal plates of the type shown in Figure 7. They are also found beneath the tubes within a cluster (Figure 6).

Since the number of wax grains is so much lower on the median than lateral seed surfaces (lemmas and paleas), it might be expected that wax from the former would contain less $\beta$ diketone and hydroxy- $\beta$-diketone than wax from the latter. TLC separation of the wax lipid classes (Figure 8) demonstrates that cer-s $\mathrm{s}^{31}$ reduces the relative importance of the $\beta$-diketone lipid classes in the waxes on the seed coats of both the lateral and median rows. Roughly equal amounts of the $\beta$-diketone lipid classes are found on hex $-v^{3}$ lateral and median rows. Similarly a significant

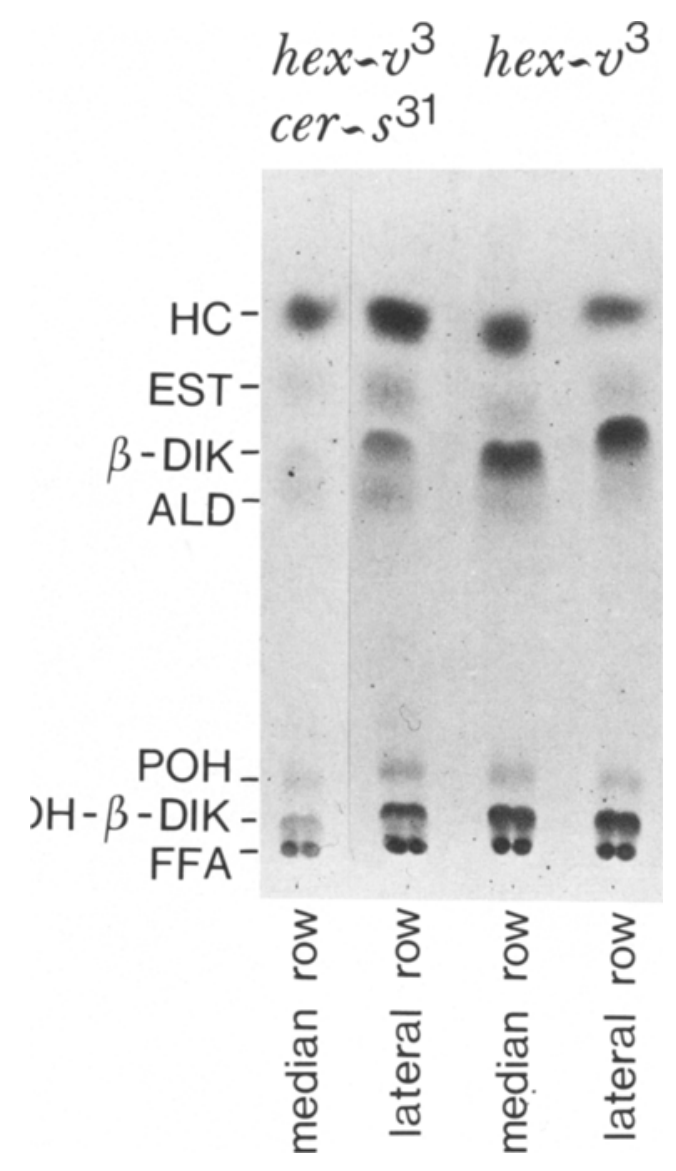

Figure 8. Composition of the epicuticular waxes of median and lateral seeds of $h e x-v^{3}$ and $h e x-v^{3} c e r-s^{31}$ spikes as revealed by TLC.

See section 2.2.

difference could not be established between the lateral and median rows of the double mutant. Analogous results are obtained from the time the first wax bloom appears on newly emerged spikes until the seeds are mature. A comparison of Figures 8 and 3 reveals that the seed surfaces contribute relatively more of the $\beta$-diketone lipid classes to total spike wax than do the glume surfaces.

\subsection{Leaf sheath waxes}

In previous studies of barley leaf sheath and internode waxes (e.g., 20, 29, 33), care has been taken to specify the uppermost internodes. Since wax isolated from the uppermost two internodes 
and sheaths consists by weight of approximately $54 \% \beta$-diketones and $20 \%$ hydroxy- $\beta$-diketones $(30,33)$, it is not surprising that they are densely covered with long, thin tubes (Figure 9, reference 29), and appear quite blue grey in color. Towards the top of the third leaf sheath, the intensity of the blue grey color often diminishes. On the lower leaf sheaths, the blue grey color is either absent or present only a short distance above the leaf sheath base. The lengths of the internodes and leaf sheaths decrease from the first (top) to the fifth internode (e.g., 29.4, 21.6, 14.3, 12.2 and $8.2 \mathrm{~cm}$ ). Figure 10, which was prepared from the fourth leaf sheath of Bonus, illustrates that plates are the dominating wax structures on the lower leaf sheaths. They can be rather similar to those found on leaf blades $(20,29)$. Other areas are characterized by less lobed plates more like those on the awns (Figure 1). If a basal area appears blue grey, however, one would expect to see wax tubes.

Mutations such as $c e r-c^{36}$ result in the loss of the blue grey color of the uppermost leaf sheaths and internodes. Earlier attempts to study wax structures present on such yellow green leaf sheaths were not very successful. The small fragments of replicas obtained were not only devoid of long, thin tubes but generally also of other well defined wax structures $(20,30)$. Use of the presently described direct platinum replica technique has revealed that the uppermost leaf sheaths of $c e r-c^{36}$ bear numerous horizontal plates (Figure 11). They are similar to the horizontal plates that have been seen, for example, on given awns (Figure 1), lemmas (Figures $6 \& 7$, references $30 \& 31$ ) and leaf blades of barley $(20,29)$. Their presence on the uppermost leaf sheaths of $c e r-c^{36}$ can at least in part explain the earlier observations that these cuticular surfaces have approximately $17 \mu \mathrm{g}$ chloroform extractable wax per $\mathrm{cm}^{2}$ which is quite similar to the 15-16 $\mu \mathrm{g}$ per $\mathrm{cm}^{2}$ on leaf blades. The latter, however, are covered with lobed vertical plates (see 30 ).

The composition of the waxes on the first and fourth leaf sheaths of Bonus as revealed by TLC is shown in Figure 12. The wax on the first leaf sheath of Bonus is characterized by dominating amounts of $\beta$-diketone lipids. Wax from the fourth leaf sheath which is dominated by primary alcohols, however, contains only a trace of $\beta$-diketone lipids, presumably from the wax present at its basal end. Isolation and characterization of the primary alcohols gave the following distribution ( $w t \%$ as acetates of important homologues): $\mathrm{C}_{20}, 0.5 ; \mathrm{C}_{22}, 2.9 ; \mathrm{C}_{24}, 4.3 ; \mathrm{C}_{26}$. 83.7; and $C_{28}, 4.4$ (see also Figure 13). This is remarkably similar to that reported (32) for the primary alcohols present on Bonus leaf blades at heading time: $\mathrm{C}_{20}, 0.5 ; \mathrm{C}_{22}, 5.3 ; \mathrm{C}_{24}, 5.2 ; \mathrm{C}_{26}$, 87.0 ; and $C_{28}, 2.0$. When wax is isolated from the first leaf sheath and acetate derivatives prepared from the lipid material present on the TLC plates at the position of primary alcohols (Figure 12), a quite different GLC spectrum is obtained. As shown in Figure 13 not only is the apparent $\mathrm{C}_{26}$ homologue less prominent, but numerous peaks that do not correspond to even chain length alcohol acetates are consistently found. No further steps were taken to identify these peaks. If the \% distribution of the apparent even number homologues is calculated, $\left(C_{22}, 2.3\right.$; $\mathrm{C}_{24}, 7.0 ; \mathrm{C}_{26}, 47.0 ; \mathrm{C}_{28}, 15.3 ; \mathrm{C}_{30}, 11.4 ; \mathrm{C}_{32}$, 15.2 ; and $\mathrm{C}_{34}, 1.7$ ) it resembles that of the primary alcohols recently reported (36) present on Bonus spikes $\left(\mathrm{C}_{22}, 1.5 ; \mathrm{C}_{24}, 6.5 ; \mathrm{C}_{26}, 50.8\right.$; $\mathrm{C}_{28}, 16.4 ; \mathrm{C}_{30}, 12.0$; and $\mathrm{C}_{32}, 9.1$ ).

Figure 12 also illustrates the lipid class composition of the waxes present on first and fourth leaf sheaths of $c^{-1}-c^{36}$. In wax from the former, the $\beta$-diketone lipid classes are absent and the relative amount of esters elevated relative to the other lipid classes, confirming previous observations $(33,36)$. The TLC picture of wax from the fourth leaf sheath of cer $-c^{36}$, however, is analogous to that from the corresponding Bonus wax preparation in that the primary alcohols dominate and the esters are not prominent.

The above data show that the relative amount and composition of the primary alcohols on the various leaf sheaths of Bonus and cer-c $c^{36}$ are correlated with the type of wax plates present on a particular surface. Vertical lobed plates are not found on the uppermost leaf sheaths of $c e r-c^{36}$ since the amount and possibly the homologue composition of the primary alcohols has not been altered concomitantly with the loss of the $\beta$ diketone lipids. An unchanged homologue composition is judged likely from the similarity of the primary alcohols in $c e r-c^{36}$ and Bonus spike waxes (36). 

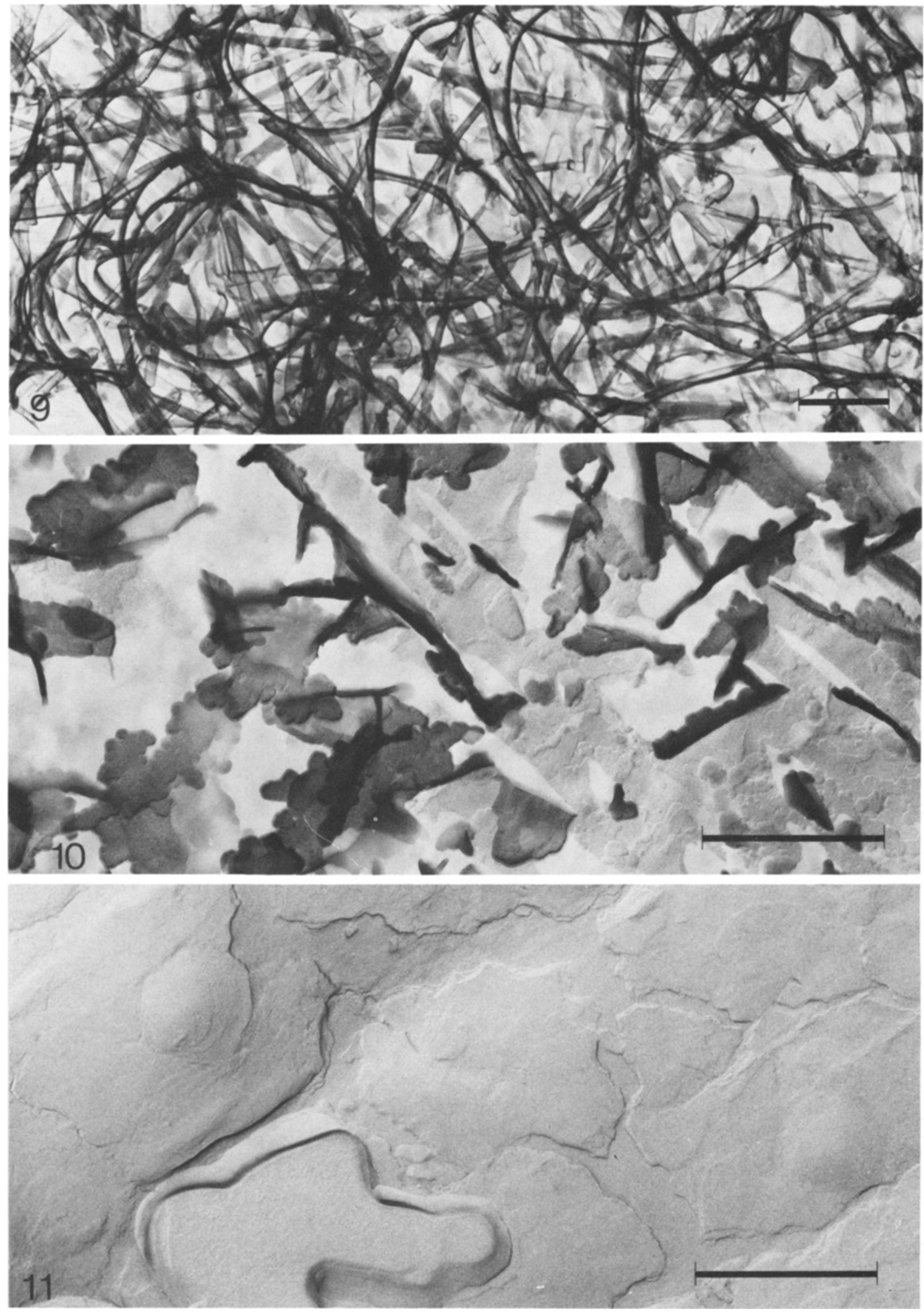
Figure 9. Dense coating of long, thin wax tubes characterizing the first (uppermost or flag) leaf sheath of Bonus barley as revealed by a $\mathrm{Pt} / \mathrm{C}$ replica from frozen tissue.

Bar $=1 \mu \mathrm{m}$.

Figure 10. Vertical and horizontal wax plates found on the fourth (from top) leaf sheath of Bonus barley as revealed by a $\mathrm{Pt} / \mathrm{C}$ replica from frozen tissue.

Bar $=1 \mu \mathrm{m}$.

Figure 11. Horizontal wax plates characterizing the cuticle surface of the first (uppermost or flag) leaf sheath of cer $-c^{36}$ barley as revealed by a $\mathrm{Pt} / \mathrm{C}$ replica from frozen tissue.

Bar $=1 \mu \mathrm{m}$.

It was noted above that the area beneath the third leaf sheath-leaf blade junction often appears somewhat greenish. The following observations on cer-p ${ }^{888}$ are pertinent in this respect. Waxes isolated from uppermost internodes plus leaf sheaths of cer- $p^{37}$ were remarkably similar to analogous Bonus preparations when analyzed by TLC and infrared spectroscopy (WETTSTEINKNOWLES, unpublished) confirming the classification of the cer-p locus as a leaf blade mutant

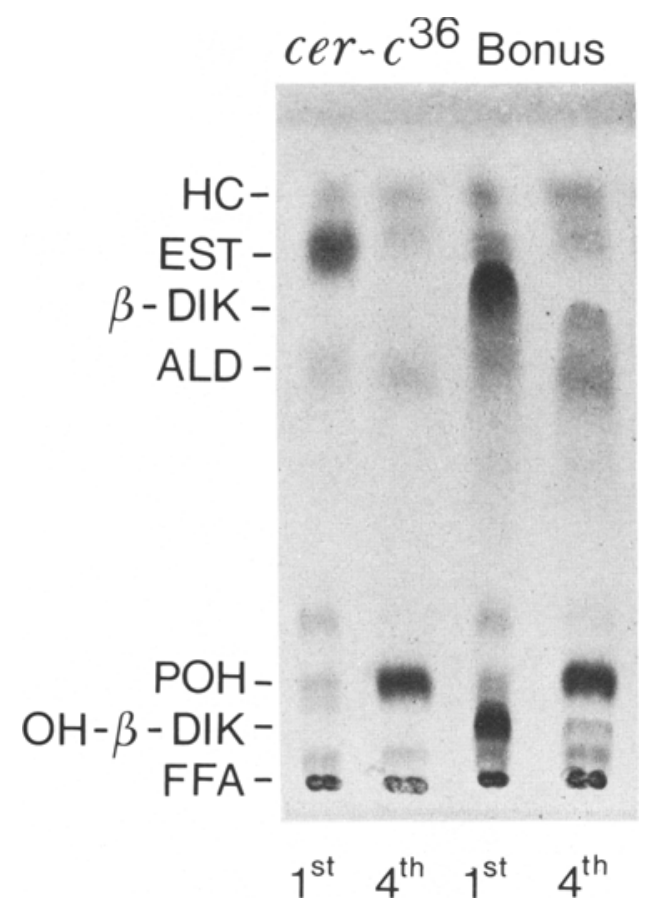

Figure 12. Composition of the epicuticular waxes isolated from the first (uppermost or flag) and fourth leaf sheaths of $c e r-c^{36}$ and Bonus barley as revealed by TLC.

See section 2.2 .
(7, 19, 29). Grey appearing leaf sheaths or segments thereof are densely coated with long, thin tubes (Figure 14) as are those of Bonus. The wax coat of the greenish segment of the third leaf sheath is somewhat variable. Both tubes and lobed plates are visible in Figure 15, while vertical plates can be seen in some areas (Figure 16). In still other areas only a few scattered or clustered tubes were found. Similar changes in types of wax structures over a relatively small

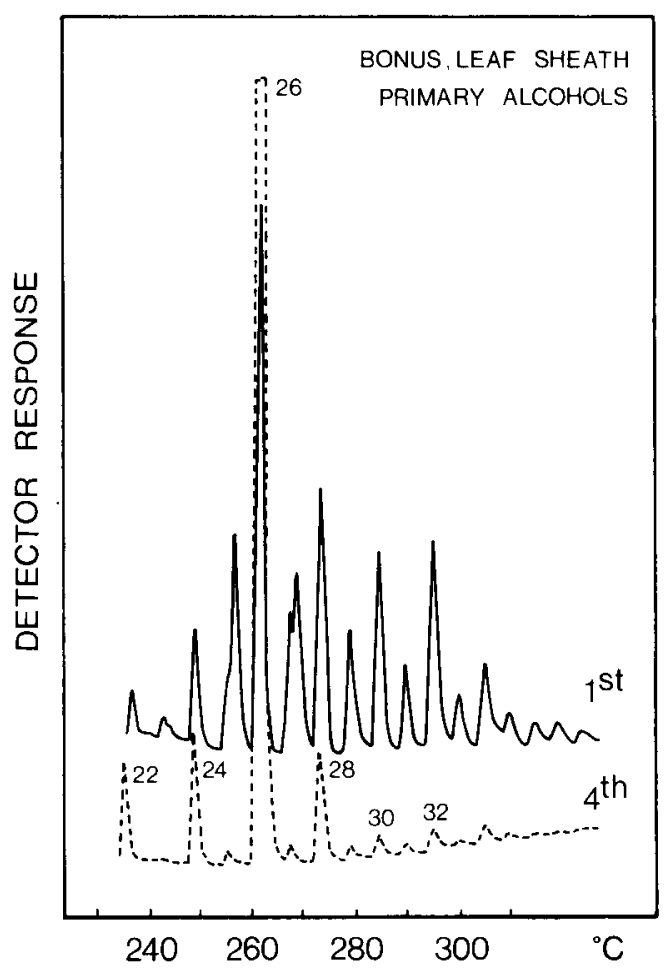

Figure 13. GLC separation of the primary alcohols as acetate derivatives from the first and fourth (from top) leaf sheaths of Bonus barley.

See section 2.2. 


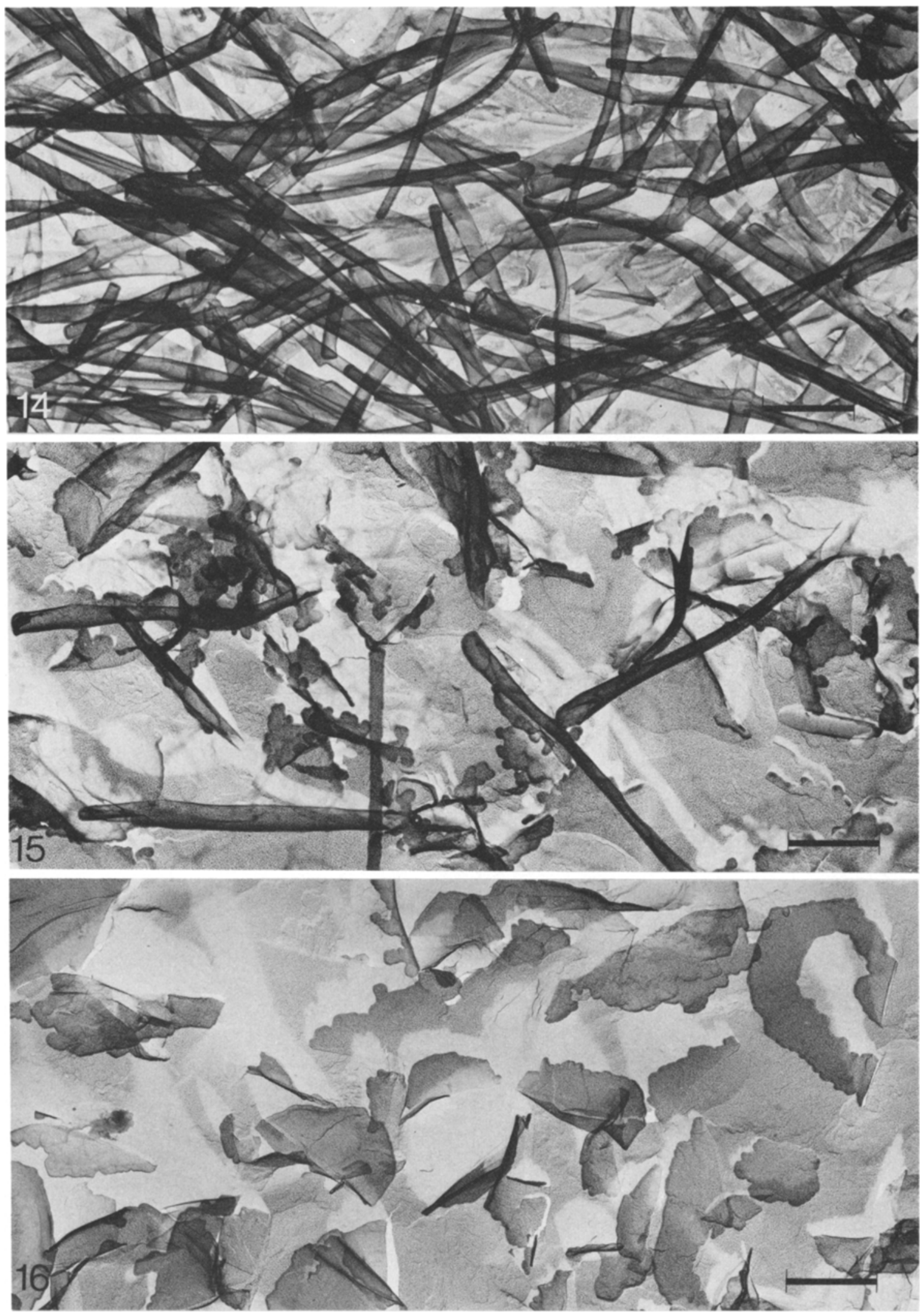


Figure 14. Dense coating of long, thin tubes characterizing the blue grey appearing cuticle surface of the second (from top) leaf sheath of $c e r-p^{888}$ barley as revealed by a $\mathrm{C} / \mathrm{Au} / \mathrm{Pd}$ replica from room temperature tissue.

$\operatorname{Bar}=1 \mu \mathrm{m}$.

Figure 15. Tubes and various types of plate waxes present in the greenish appearing segment just below the leaf blade of the third (from top) leaf sheath of $c e r-p^{888}$ barley as revealed by a $\mathrm{C} / \mathrm{Au} / \mathrm{Pd}$ replica from room temperature tissue.

$\mathrm{Bar}=1 \mu \mathrm{m}$.

Figure 16. Vertical and horizontal plate waxes present in the greenish appearing segment just below the leaf blade of the third (from top) leaf sheath of cer- $p^{888}$ barley as revealed by a C/Au/Pd replica from room temperature tissue.

$\operatorname{Bar}=1 \mu \mathrm{m}$.

surface area were found on the glumes of some Avena species in a scanning electron microscopic survey (4). The lipid class compositions of the waxes from the greenish and blue grey areas of the third leaf sheath in cer-p ${ }^{888}$ (Figure 17) are analogous to those found on the fourth and first leaf sheath waxes of Bonus, respectively (Figure 12). Compared to the latter, cer- $p^{888}$ leaf sheath waxes contain a relatively greater amount of aldehydes.

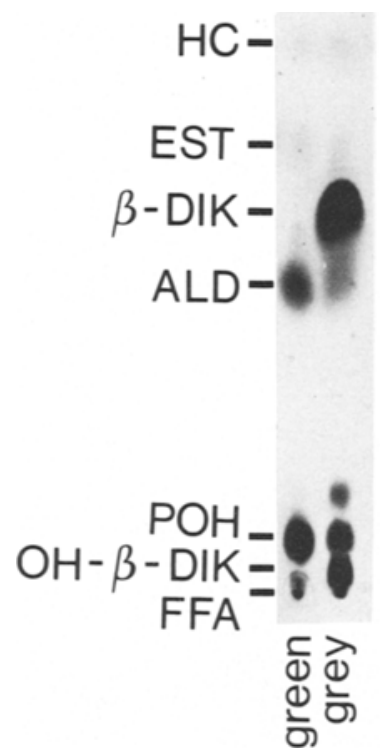

Figure 17. Composition of the epicuticular waxes from greenish and blue grey segments of the third (from top) leaf sheath of $c e r-p^{888}$ barley as revealed by TLC.

See section 2.2 .

\subsection{Structure of plate waxes}

In the above presentation a number of different adjectives has been used to describe the structure of a wax plate, a major division being horizontal vs vertical position. The latter type often appears as thin, flake-like structures the edges of which are lobed to varying degrees. When a wax coating is reasonably dense, such as that of barley basal leaf sheaths (Figure 10), barley and most wheat leaf blades (e.g., 22, 29) and other surfaces high in primary alcohols (e.g., $3,6,12,14,22,29$ ), it is often difficult to discriminate between individual plates and to characterize their shape. A technique that might be useful in this respect is that of negative staining which has been successfully used in studies of wax tubes $(3,15,16)$. The plates were gently removed by a drop of staining solution when it was touched to the cuticle surface (31). The negatively stained small plates are seen to be flake-like and to exhibit a high degree of lobing (Figure 18). As a control a negative stain preparation of portions of long, thin tubes and large irregular plates is shown in Figure 19. Similar structures to those in Figures $18 \& 19$ are present in replicas made from corresponding cuticle surfaces (see Figure $3 a \& b$ in reference 22).

This technique for studying wax plates also has the potential to reveal aspects of the structural nature of the more complex bodies observed in replicas of plate bearing wax surfaces. For example, are the wax bodies characteristic of cuticle surfaces with large amounts of primary alcohols a single continuous structure, as suggested by MARTIN and JUNIPER's 


\section{Simpson and P. von WetTstein-KNowles: Structure of barley waxes}
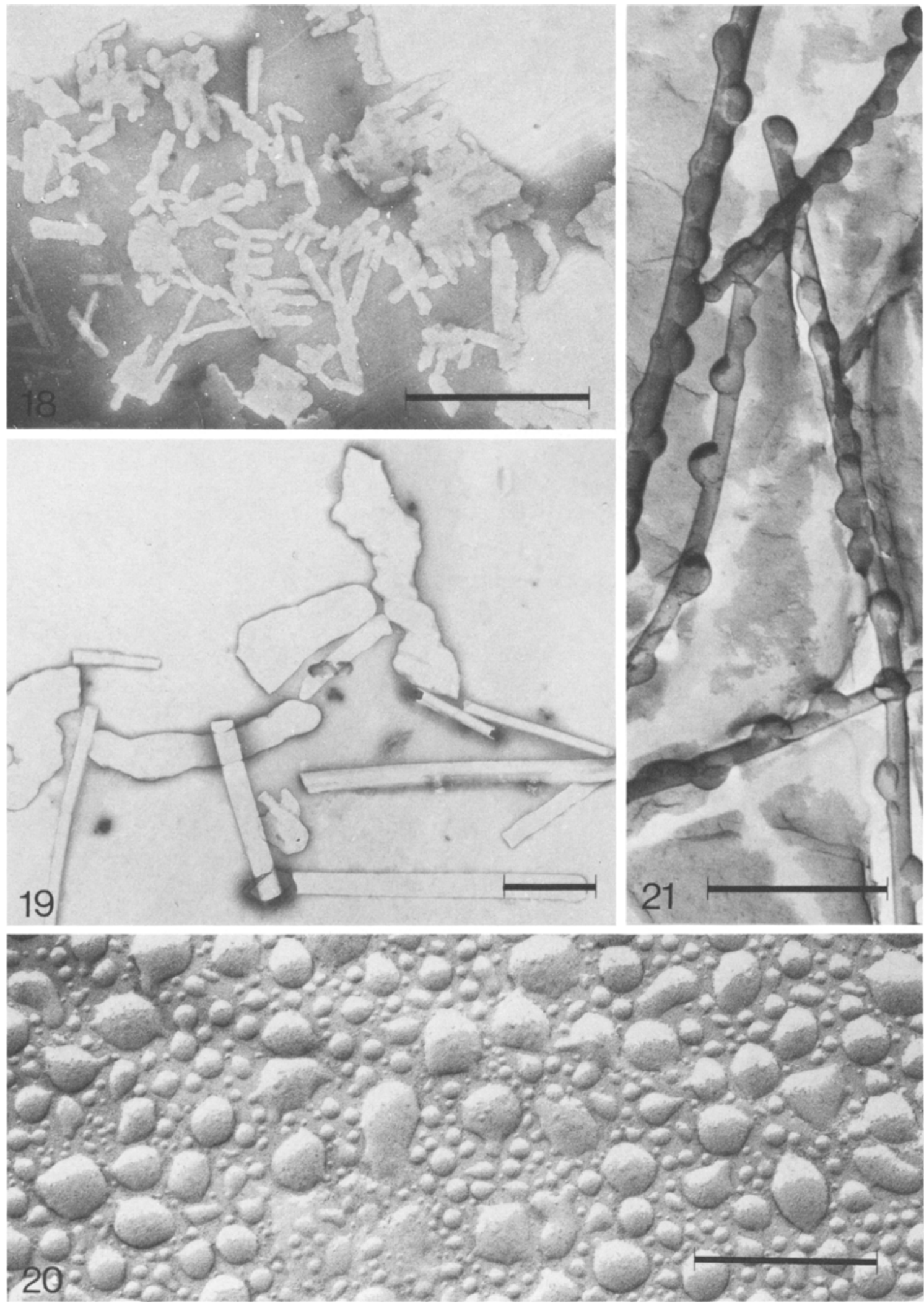
Figure 18. Negatively stained small thin wax plates or fragments thereof from the adaxial surface at the base of a flag leaf of Chinese Spring wheat.

Bar $=1 \mu \mathrm{m}$.

Figure 19. Negatively stained portions of wax tubes, slightly lobed thin plates and fragments of small wax plates from the abaxial surface at the base of a flag leaf of Chinese Spring wheat.

$\operatorname{Bar}=1 \mu \mathrm{m}$.

Figure 20. Water vapor contaminating a cuticle surface lacking vertical plates or tubes caused by cooling the specimen before a good vacuum was reached during preparation of a $\mathrm{Pt} / \mathrm{C}$ replica.

$\operatorname{Bar}=1 \mu \mathrm{m}$.

Figure 21. Water vapor contaminating wax tubes resulting from cooling the specimen before a good vacuum was attained during preparation of a $\mathrm{Pt} / \mathrm{C}$ replica.

$\operatorname{Bar}=1 \mu \mathrm{m}$.

interpretation (see p. 108 of their book, 21), or are they made up of individual juxtaposed flakelike plates that remain distinct entities. Although such an investigation is outside the scope of the present paper, the result shown in Figure 18 could be interpreted to support the latter idea.

\subsection{The direct platinum shadowed replica technique}

Numerous modifications for improving the preparation of heavy metal shadowed carbon replicas from plant tissue surfaces for examination in the transmission electron microscope have been described (e.g., 1, 5, 10,11, 13, 38) since the introduction of this approach by JUNIPER and BRADLEY in 1958 (17). In addition, we are aware of two laboratories that have described the successful preparation of platinum shadowed replicas at room temperature $(1,2,28$, 37). All these methods have in common the attribute that replicas are more easily prepared from tissue surfaces bearing a heavy coat of wax projecting from it. The method used herein involves making a direct platinum replica of the frozen $\left(-100^{\circ} \mathrm{C}\right)$ surface of the plant material. It has the advantage of producing high resolution replicas in a short time with relative ease from tissue surfaces that have few or no projecting wax structures (Figures 1, 7, \& 11). One factor contributing to our success may have been that unlike all previous workers with the exception of THAIR and Lister (28), we did not back the replica and then strip it from the tissue. Instead, the tissue was removed from the replica with the aid of chromic acid and acetone (see section 2.3). THAIR and LISTER used diethyl ether which was effective on their very waxy Douglas fir (Pseudotsuga menziezii) needles. The size of the replicas obtained from surfaces with smooth layers of wax or those apparently lacking wax structures (3) are considerably smaller, maximally $0.25 \mathrm{~mm}^{2}$, than those prepared from surfaces with projecting wax structures such as Bonus leaf sheaths. The latter were equivalent in area, several $\mathrm{mm}^{2}$, to the specimen size. In this connection it is interesting to note that preparation of high resolution, pre-shadowed surface replicas need not be limited to surfaces coated with wax, but has been applied to the study of the fine structure of the Drosophila eye (26).

The use of low specimen temperature enables the wax structures to withstand the heat load during heavy metal deposition. To circumvent this problem RENTSCHLER (23) resorted to freezing the tissue before placing it in a vacuum chamber for replica preparation. We have found, however, that care must be taken to delay specimen cooling until a good vacuum has been reached to avoid contamination of the surface with water vapor (Figures 20 \& 21). This phenomenon may be responsible for the anomolous appearance of wax structures reported by some workers $(9,23,24)$. The low temperature also improves resolution by increasing the density of crystal nucleation sites, thereby reducing metal grain size (25).

The present modification is no more successful than other replication techniques for studying extremely irregular surfaces, such as the abaxial 
one of a barley glume. The mechanical stability of a replica from such a surface is not great enough to allow its separation from the underlying organic material by either chemical or mechanical methods. On the other hand, replicas could be prepared from the approximately triangular shaped, long narrow awns that have relatively little projecting wax, which one of us had been unable to successfully replicate with the gold-palladium pre-shadowed carbon replica technique.

\section{ACKNOWLEDGEMENTS}

We are indebted to $J$. NIELSEN and $M$. PETERSEN for outstanding technical assistance; to U. Lundevist and Dr. B. SøgaARd for making the crosses; to the personnel of the Phytotron in Stockholm and B. Petersen for looking after the plants; to Dr. G. GibBons for taking the pictures of the seeds; and to A.-S. Steinholz and N. RASMUSSEN for preparing the figures.

\section{REFERENCES}

1. Armstrong, D. J.: Aspects on the formation and temperature modification of leaf surface wax in Brassica napus L. PhD. Thesis, Australian National University, Canberra, Australia (1973)

2. Armstrong, D. J. \& M. I. Whitecross: Temperature effects on formation and fine structure of Brassica napus leaf waxes. Aust. J. Bot. 24, 309-318 (1976)

3. Avato, P., J. D. Mikkelsen \& P. von WettSTEIN-KNOWLES: Effect of inhibitors on synthesis of fatty acyl chains present in waxes on developing maize leaves. Carlsberg Res. Commun. 45, 329-347 (1980)

4. Baum, B. R. \& V. E. Hadland: The epicuticular waxes of glumes of Avena: a scanning electron microscopic study of the morphological patterns in all the species. Can. J. Bot. 53, 1712-1718 (1975)

5. Chambers, T. C., I. M. Ritchie \& M. A. Booth: Chemical models for plant wax morphogenesis. New Phytol. 77, 43-49 (1976)

6. Davis, D. G.: Scanning electron microscopic studies of wax formations on leaves of higher plants. Can. J. Bot. 49, 543-546 (1971)

7. Giese, B. N.: Roles of the cer-j and cer-p loci in determining the epicuticular wax composition on barley seedling leaves. Hereditas (Lund) 82 , $137-148(1976)$
8. Gustafsson, A., A. Hagberg, U. Lundquist \& G. Persson: A proposed system of symbols for the collection of barley mutants at Svalof. Hereditas (Lund) 62, 409-414 (1969)

9. HAAS, K. \& I. RentsCHLER: Structure and composition of the cuticular wax of Trifolium hybridum L. Cytobiologie 12, 215-219 (1976)

10. Hall, D. M.: A study of the surface wax deposits on apple fruit. Aust. J. Biol. Sci. 19, 1017-1025 (1966)

11. Hall, D. M. \& L. A. Donaldson: The ultrastructure of wax deposits on plant leaf surfaces I. Growth of wax on leaves of Trifolium repens. J. Ultrastruct. Res. 9, 259-267 (1963)

12. Hall, D. M., A. I. Matus, J. A. Lamberton \& H. N. BARBER: Infra-specific variation in wax on leaf surfaces. Aust. J. Biol. Sci. 18, 323-332 (1965)

13. Hallam, N. D.: Sectioning and electron microscopy of eucalypt leaf waxes. Aust. J. Biol. Sci. 17, 587-590 (1964)

14. Holloway, P. J., G. M. Hunt, E. A. Baker \& M. J. K. MACEY: Chemical composition and ultrastructure of the epicuticular wax in four mutants of Pisum sativum (L). Chem. Phys. Lipids 20, 141-155 (1977)

15. Jeffree, C. E., E. A. Baker P. J. Holloway: Origins of the fine structure of plant epicuticular waxes. In: Microbiology of aerial plant surfaces. Dickinson, C. H. \& T. F. Preece, eds., Academic Press Inc., London pp. 118-158 (1976)

16. Johnson, R. P. C. \& C. E. Jefrree: Negative stain in wax tubes from the surface of Sitka spruce leaves. Planta (Berl.) 95, 179-182 (1970)

17. Juniper, B. E. \& D. E. Bradley: The carbon replica technique in the study of the ultrastructure of leaf surfaces. J. Ultrastruct. Res. 2, 1627 (1958)

18. Lundqvist, U. \& D. von WetTSTEIN: Induction of eceriferum mutants in barley by ionizing radiations and chemical mutagens. Hereditas (Lund) 48, 342-362 (1962)

19. Lundevist, U. \& D. von Wettstein: Stock list for the eceriferum mutants III. Barley Genetics Newsletter 5, 88-90 (1975)

20. Lundqvist, U., P. von Wettstein-Knowles \& D. VON WETTSTEIN: Induction of eceriferum mutants in barley by ionizing radiations and chemical mutagens II. Hereditas (Lund) 59, 473504 (1968)

21. Martin, J. T. \& B. E. Juniper: The cuticles of plants. Edward Arnold Publishers Ltd., London (1970)

22. Netting, A. G. \& P. von Wettstein-Knowles: The physico-chemical basis of leaf wettability in wheat. Planta (Berl.) 114, 289-309 (1973) 
23. Rentschler, I.: Crystalline and noncrystalline waxes on the surfaces of leaves. Cytobiologie 3 , 172-175 (1971)

24. ReNTSChleR, I.: On the preparation of the wax layer of plant leaves for electron microscopy. Microscopia Acta 82, 47-52 (1979)

25. Slayter, H. S.: High-resolution metal replication of macromolecules. Ultramicroscopy 1 , 341-357 (1976)

26. SteERe, R. L.: Ultrastructural details as revealed by stereo transmission electron microscopy of high resolution, pre-shadowed surface and freeze-etch replicas: sample - the Drosophila eye. Ninth Internat. Congr. Electr. Microsc., Toronto Vol. II, 144-145 (1978)

27. Søgaard, B.: Linkage studies on eceriferum mutants in barley. Barley Genetics Newsletter 1 , 41-47 (1971)

28. Thair, B. W. \& G. R. Lister: The distribution and fine structure of the epicuticular leaf wax of Pseudotsuga menziezii. Can J. Bot. 53, 10631071 (1975)

29. Wettstein-Knowles, P. von: The molecular phenotypes of the eceriferum mutants. In: Proc. 2nd Int. Barley Genet. Symp. (1969) R. A. Nilan, ed., Pullman, Wash., USA, Washington State Univ. Press, pp. 146-193 (1971)

30. Wettstein-Knowles, P. von: Genetic control of $\beta$-diketone and hydroxy- $\beta$-diketone synthesis in epicuticular waxes of barley. Planta (Berl.) 106, 113-130 (1972)

31. Wettstein-Knowles, P. von: Ultrastructure and origin of epicuticular wax tubes. J. Ultrastruct. Res. 46, 483-498 (1974)

32. Wettstein-Knowles, P. von: Gene mutation in barley inhibiting the production and use of $\mathrm{C}_{26}$ chains in epicuticular wax formation. FEBS Lett. 42, 187-191 (1974)

33. Wettstein-Knowles, P. von: Biosynthetic relationships between $\beta$-diketones and esterified alkan-2-ols deduced from epicuticular wax of barley mutants. Molec. gen. Genet. 144, 43-48 (1976)

34. Wettstein Knowles, P. von: Genetics and biosynthesis of plant epicuticular waxes. In: Advances in the biochemistry and physiology of plant lipids. L. Á. Appelqvist \& C. Liljenberg, eds., Elsevier/North Holland Biomedical Press. Amsterdam. pp. 1-26 (1979)

35. Wettstein-Knowles, P. von \& A. G. Netting: Composition of epicuticular waxes on barley spikes. Carlsberg Res. Commun. 41, 225-235 (1976)

36. Wettstein-Knowles, P. von \& B. SøgaARD: The cer-cqu region in barley: gene cluster or multifunctional gene. Carlsberg Res. Commun. 45, 125-141 (1980)

37. Whitecross, M. I. \& D. J. Armstrong: Environmental effects of epicuticular waxes of Brassica napus J. Aust. J. Bot. 20, 87-95 (1972)

38. Williams, P. R. \& B. E. JunipeR: An improved replica technique for examining plant surfaces in the electron microscope. Proc. R. Microsc. Soc. 3, 129-131 (1968) 